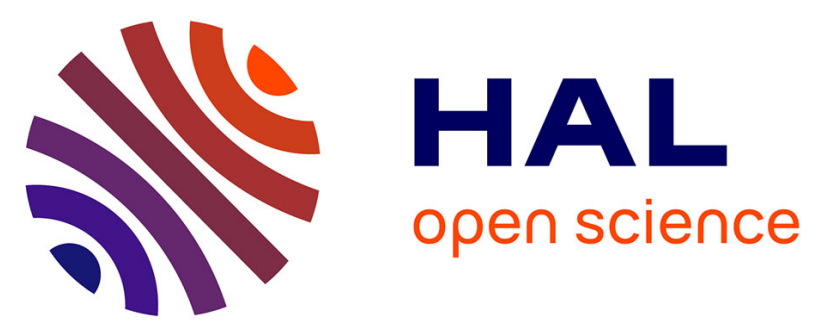

\title{
Atomic Layer Deposition of Pd Nanoparticles on TiO2 Nanotubes for Ethanol Electrooxidation: Synthesis and Electrochemical Properties
}

\author{
Loïc Assaud, Nicolas Brazeau, Maïssa K. S. Barr, Margrit Hanbücken, \\ Spyridon Ntais, E. A. Baranova, Lionel Santinacci
}

\section{To cite this version:}

Loïc Assaud, Nicolas Brazeau, Maïssa K. S. Barr, Margrit Hanbücken, Spyridon Ntais, et al.. Atomic Layer Deposition of Pd Nanoparticles on TiO2 Nanotubes for Ethanol Electrooxidation: Synthesis and Electrochemical Properties. ACS Applied Materials \& Interfaces, 2015, 7 (44), pp.24533-24542. 10.1021/acsami.5b06056 . hal-03164021

\section{HAL Id: hal-03164021 \\ https://hal.science/hal-03164021}

Submitted on 9 Mar 2021

HAL is a multi-disciplinary open access archive for the deposit and dissemination of scientific research documents, whether they are published or not. The documents may come from teaching and research institutions in France or abroad, or from public or private research centers.
L'archive ouverte pluridisciplinaire HAL, est destinée au dépôt et à la diffusion de documents scientifiques de niveau recherche, publiés ou non, émanant des établissements d'enseignement et de recherche français ou étrangers, des laboratoires publics ou privés. 


\section{Atomic Layer Deposition of Pd Nanoparticles on}

\section{$\mathrm{TiO}_{2}$ nanotubes for Ethanol Electrooxidation:}

\section{Synthesis and Electrochemical Properties}

Loïc Assaud ${ }^{\dagger,, \perp}$, Nicolas Brazeau ${ }^{*}, \perp$, Maïssa K. S. Barr ${ }^{\dagger}$, Margrit Hanbücken $\dagger$, Spyridon Ntais ${ }^{\ddagger}$, Elena. A. Baranova ${ }^{\ddagger, *}$ and Lionel Santinacci ${ }^{\dagger, *}$

$\dagger$ Aix Marseille Université, CNRS, CINaM UMR 7325, 13288, Marseille, France

$\$$ Department of Chemical and Biological Engineering, Center for Catalysis Research and Innovation, University of Ottawa, 161 Louis-Pasteur St., Ottawa, ON, K1N 6N5, Canada

KEYWORDS: atomic layer deposition, electrocatalysis, direct ethanol fuel cells, titanium dioxide, palladium, nanotubes, nanoparticles.

ABSTRACT. Palladium nanoparticles are grown on $\mathrm{TiO}_{2}$ nanotubes by atomic layer deposition (ALD) and the resulting three dimensional nanostructured catalysts are studied for ethanol electrooxidation in alkaline media. The morphology, the crystal structure and the chemical composition of the Pd particles are fully characterized using scanning and transmission electron microscopies, x-ray diffraction and x-ray photoelectron spectroscopy. The characterization revealed that the deposition proceeds onto the entire surface of the $\mathrm{TiO}_{2}$ nanotubes leading to the formation of well-defined and highly dispersed Pd nanoparticles. The electrooxidation of ethanol 
on $\mathrm{Pd}$ clusters deposited on $\mathrm{TiO}_{2}$ nanotubes show not only a direct correlation between the catalytic activity and the particle size but also a steep increase of the response due to the enhancement of the metal-support interaction when the crystal structure of the $\mathrm{TiO}_{2}$ nanotubes is modified by annealing at $450^{\circ} \mathrm{C}$ in air.

\section{Introduction}

The hydrogen-based production of energy is attracting more and more attention especially in fuel cells technology due to the high energy density of hydrogen. However, the $\mathrm{H}_{2}$ storage and transportation is still a challenge. The new generation of fuel cells based on the electrooxidation of alcohols such as methanol, ethanol or ethylene glycol is an interesting alternative for the production of energy. ${ }^{1}$ Among them, methanol and ethanol are the most promising fuels, however ethanol exhibits two key advantages over methanol: it is non-toxic and renewable fuel that can be extracted from the biomass. ${ }^{2}$

The kinetics of the ethanol oxidation reaction (EOR) is slow in acidic media and incomplete oxidation is generally achieved over Pt-based catalysts resulting in production of acetaldehyde and acetic acid. ${ }^{3}$ To overcome this issue, it is possible to electrooxidize ethanol in alkaline media, where oxidation kinetics is favorable and it allows the use of a cheaper Pd-based systems. ${ }^{1,4}$ Various strategies aimed at further improving the catalytic activity of Pd have been

proposed. ${ }^{1}$ One of them is the addition of a second noble $(\mathrm{Ru}, \mathrm{Au}, \mathrm{Ir})$ or non-noble $(\mathrm{Ni}, \mathrm{Sn})$ metal to Pd proved to be advantageous. ${ }^{1,5-8}$ Another approach is the use of the appropriate supporting material that can finely disperse and stabilize Pd nanoparticles as well as show better stability than conventional carbon black., ${ }^{1,5}$ The catalyst support can further influence strongly the activity of the metallic particles via metal-support interaction (MSI). ${ }^{9-11}$ The catalyst support can have an 
impact on the catalyst dispersion, size and morphology. Furthermore, it can modify the electronic properties of the catalyst by changing the adsorption strength of ethanol and reaction intermediates resulting in improved catalyst stability and reactivity. The carbon-based materials are widely used as a support material in fuel cells, however carbon is not stable and corrodes under reaction conditions. In order to improve the catalyst support, it can be nanostructured (e. g. carbon nanotubes ${ }^{12}$ ) or other materials such as $\mathrm{TiO}_{2}$ can be used..$^{13}$ Titanium dioxide is known for its high stability and that in contact with platinum group metals it shows strong metal-support interaction (SMSI) for gas phase catalytic reactions..$^{9}$ Among the numerous types of titanium dioxide nanostructures, $\mathrm{TiO}_{2}$ nanotubes (TNTs) are very interesting, because they have a large specific area and well-defined geometry. TNTs can be obtained by various methods such as deposition in templates, molecular assembly templating, hydrothermal reaction, electrospinning and anodic oxidation. ${ }^{14}$ The later method is straightforward and offers a large control of the tube morphology. In anodic TNTs, the charge transport and collection are facilitated by the nanotubes self-alignment, because they are connected by the Ti substrate.

The coupling of Pd nanoparticles with TNTs has been reported recently. The Pd catalysts were either chemically deposited in porous $\mathrm{TiO}_{2}{ }^{15-16}$ or electrochemically deposited on anodic TNTs. ${ }^{17}$ Atomic layer deposition (ALD) is a method of choice to grow continuous thin layers on threedimensional substrates exhibiting a high aspect ratio. ${ }^{18-20}$ ALD has been used to grow oxide films to support the catalysts. More recently, it has been applied to preserve the catalysts with an ultrathin metal oxide layer or to directly grow metallic nanoparticles (see, e.g., the reviews ${ }^{21-23}$ ). In the later case, ALD is particularly interesting because it provides a precise control of the growth rate and composition of the catalyst on tortuous nanostructures ${ }^{24-25}$ Furthermore, metallic nanoparticles deposited by ALD exhibit similar or better catalytic activities than those grown by 
other techniques, such as impregnation, ion-exchange, and deposition-precipitation. ${ }^{26-27}$ In the recent years, several works have shown the interest of using ALD to conformally grow catalytic nanoparticles onto nanostructured substrates. Pt has been deposited onto various substrates such as $\mathrm{ZnO}$ or $\mathrm{TiO}_{2}$ for alcohol oxidation, oxygen reduction or photocatalysis..$^{25,28-30} \mathrm{Pd}$ has been less experienced but Feng et al. ${ }^{31}$ and Rikkinen et al. ${ }^{32}$ report the efficient deposition of this metal onto planar $\mathrm{Al}_{2} \mathrm{O}_{3}, \mathrm{ZnO}$ and porous carbon. The aim of the present study is to conformally coat TNTs with uniformly distributed Pd clusters and to assess their promising electroactivity. The Pd nanoparticles have been grown by ALD onto anodic TNTs (Pd/TNTs). The morphology, the chemical composition and the crystal structure of the metallic clusters have been investigated in details by scanning and transmission electron microscopies (SEM, TEM), x-ray photoelectron spectroscopy (XPS) and x-ray diffraction. The electroactivity of Pd/TNTs toward ethanol electrooxidation has been evaluated by cyclic voltammetry (CV) and chronoamperometry (CA) as a function of the ALD parameters and depending on the crystalline structure of the TNTs.

\section{Experimental}

\section{Preparation of $\mathrm{TiO}_{2}$ nanotubes}

The catalyst support consists of $\mathrm{TiO}_{2}$ nanotubes electrochemically grown from titanium foils (Advent, $95.6 \%$ purity) in an aqueous fluoride containing acidic electrolyte $(1 \mathrm{M} \mathrm{NaOH}+1 \mathrm{M}$ $\left.\mathrm{H}_{3} \mathrm{PO}_{4}+0.5 \% \mathrm{HF}\right)$. Ti samples were cut in square pieces $\left(2 \times 2 \mathrm{~cm}^{2}\right)$ then cleaned successively by sonicating in acetone, isopropanol and methanol baths for $5 \mathrm{~min}$ and, finally, rinsed in deionized water and dried under a nitrogen stream. The nanotubes were grown in a teflon electrochemical cell with a circular opening exposing $1.13 \mathrm{~cm}^{2}$ of the sample to the solution. The Ti foils, a Pt mesh and a mercury/mercurous sulfate electrode (MSE, $E^{\circ}=0.64 \mathrm{~V}$ vs SHE) 
served as working, counter and reference electrodes, respectively. The nanotubes were grown at room temperature under an applied potential $(U)$ of $20 \mathrm{~V}$ using a high voltage potentiostat (Modulab, Solartron Analytical). The duration of the anodization was $1 \mathrm{~h}$ in order to grow $1 \mu \mathrm{m}$ long nanotubes. In some cases, the TNTs were annealed in air at $450^{\circ} \mathrm{C}$ for $2 \mathrm{~h}$ to modify their crystal structure.

\section{Atomic layer deposition of $P d$}

The catalysts were synthesized by atomic layer deposition in a Fiji 200 reactor from Ultratech/Cambridge Nanotech. As previously reported, ${ }^{33}$ the Pd deposition was carried out with palladium(II)hexafluoroacetylacetonate $\left(\mathrm{Pd}(\mathrm{hfac})_{2}, 98 \%\right.$ from Strem Chemicals) and formalin (37\% formaldehyde in water with $10-15 \%$ of methanol from Sigma Aldrich). The Pd canister was maintained at $90^{\circ} \mathrm{C}$ while the temperature of the reaction chamber was set to $200^{\circ} \mathrm{C}$. The ALD cycle consisted of sequential pulse, exposure and purge of Pd precursor and formalin, alternatively. The pulse, exposure and purge durations were 1:30:30 $\mathrm{s}$ and 3:30:30 s for $\operatorname{Pd}(\mathrm{hfac})_{2}$ and formalin, respectively. To increase the transport of the $\mathrm{Pd}(\mathrm{hfac})_{2}$ toward the chamber, Ar was injected for $0.25 \mathrm{~s}$ into the canister prior to each $\mathrm{Pd}(\mathrm{hfac})_{2}$ pulse. The ALD of Pd was performed on both TNTs and flat Si (100) substrates in order to facilitate some characterizations. The number of ALD cycles $(N)$ was varied in order to adjust the catalyst loading.

\section{Characterization methods}

The morphologies of TNTs as well as the supported Pd nanoparticles were characterized by scanning and transmission electron microscopies using JEOL 6320F and JEOL 7800F SEMs and a JEOL 3010 TEM. The crystal structures of the Pd clusters and $\mathrm{TiO}_{2}$ substrate were analyzed by x-ray diffraction (XRD) using a Rigaku RU-200 rotating anode x-ray generator (operating power $40 \mathrm{kV} / 30 \mathrm{~mA}$ ) equipped with a Xenocs Fox3D Cu 12_INF mirror and a Mar345 image plate 
detector from Rayonix. X-ray photoelectron spectroscopy measurements were performed in a KRATOS Axis Ultra DLD with a Hybrid lens mode at $140 \mathrm{~W}$ and pass energy of $20 \mathrm{eV}$ using a monochromatic Al Ka. The Pd3d and Ti2p XPS core level spectra were analyzed using a fitting routine which decomposes each spectrum into individual mixed Gaussian-Lorentzian peaks using a Shirley background subtraction over the energy range of the fit. The deconvolution of $\mathrm{Pd} 3 \mathrm{~d}$ was performed using doublets with spin orbit splitting (SOS) $5.3 \mathrm{eV}$ and intensity ratio $\operatorname{Pd} 3 d_{5 / 2}: \operatorname{Pd} 3 d_{3 / 2}=3 / 2^{34}$ while a peak asymmetry was used in the case of the Pd $3 d$ peak attributed to the metallic state based on the work of Hufner et al. ${ }^{35}$ The Ti2p spectra were analyzed using doublets with $\mathrm{SOS}=5.7 \mathrm{eV}$ and intensity ratio Ti2 $\mathrm{p}_{3 / 2}: \mathrm{Ti} 2 \mathrm{p}_{1 / 2}=2 / 1 .{ }^{36}$ The Binding energy $(\mathrm{BE})$ was corrected using the $\mathrm{C} 1 \mathrm{~s}$ peak at $284.8 \mathrm{eV}$ as an internal standard. The accuracy of measurement of the binding energy is $\pm 0.1 \mathrm{eV}$ while that of full width at half maximum $(\mathrm{FWHM})$ is $\pm 0.05 \mathrm{eV}$.

\section{Electrochemical characterizations}

The electrochemical characterizations of Pd/TNTs were carried out using a BioLogic potentiostat/galvanostat in $1 \mathrm{M} \mathrm{KOH}$ with and without $1 \mathrm{M} \mathrm{C}_{2} \mathrm{H}_{5} \mathrm{OH}$. The reference electrode used was a $\mathrm{Hg} / \mathrm{HgO}\left(\mathrm{MMO}, E^{\circ}=0.098\right.$ vs $\left.\mathrm{SHE}\right)$ and the counter electrode was a large surface area $\mathrm{Pt}$ mesh. Cyclic voltammetry $(\mathrm{CV})$ were recorded at a scan rate of $25 \mathrm{mV} \mathrm{s}^{-1}$ unless otherwise stated. Chronoamperograms (CA) were obtained by holding the potential at $-0.6 \mathrm{~V}$ vs MMO for $5 \mathrm{~min}$ then stepping to $-0.2 \mathrm{~V}$ for $1 \mathrm{~h}$. The electrochemical active surface area (ECSA) was determined by the reduction of a full monolayer of $\mathrm{PdO}$ in $0.5 \mathrm{M} \mathrm{H}_{2} \mathrm{SO}_{4} \cdot{ }^{37}$ In the following, the current density is plotted either against the geometric area of the electrode (noted “GEOM”) or against the ECSA. 


\section{Results and discussion}

\section{Synthesis and characterization of the catalysts}

Figure 1 shows a cross-section and a top view (inset) of the nanotubes grown at $U=20 \mathrm{~V}$ for $1 \mathrm{~h}$. The typical self-ordered morphology of TNTs is observed on the SEM micrographs. The tubular features (and not pores) separated by interstitial voids are uniformly distributed over the whole sample. Since an aqueous electrolyte has been used, the tube walls have a wavy aspect. The diameter of the tubes is about $70 \mathrm{~nm}$, the length is approximately $1 \mu \mathrm{m}$ and the wall thickness is in the range of $10 \mathrm{~nm}$. The as-formed nanotubes are amorphous but after annealing in air for $2 \mathrm{~h}$ at $450^{\circ} \mathrm{C}$, they are converted to the anatase crystal phase. Although their morphology remains unchanged their physical properties such as conductivity, photo-conversion efficiency or catalytic activity can be drastically modified and, in some cases, improved. ${ }^{14}$ In a previous study, the optimal annealing parameters (temperature, duration and atmosphere) have been described ${ }^{38}$ In the following, the Pd deposition has always been performed on TNTs grown under similar conditions as presented in Figure 1 with or without a subsequent annealing step.

The Pd deposition process and mechanism have been already described in several reports ${ }^{33,39-40}$ and will not be described again here. Figure 2 presents the evolution of the Pd deposit with respect to the number of ALD cycles ( $N$ ranging from 400 to 900 cycles). Although ALD is generally used to grow a continuous film, the SEM top views show nanoparticles uniformly spread over the samples. This is due to the high difference of surface energies between the metal and the oxidized support. ${ }^{41}$ This has been clearly illustrated by the study of the selective Pt growth over Pd clusters that were previously deposited on $\mathrm{Al}_{2} \mathrm{O}_{3}{ }^{42}$ The authors report that the $\mathrm{Pt}$ nucleation occurs selectively onto the Pd clusters because the nucleation on alumina is not thermodynamically favored. In the present work, almost no Pd is detected by SEM or XRD for 
$N<200$ cycles. A nucleation delay of several hundreds of cycles has been observed for Pd deposition onto $\mathrm{Al}_{2} \mathrm{O}_{3}$ from $\mathrm{Pd}(\mathrm{hfac})_{2}$ and formalin or $\mathrm{H}_{2}{ }^{39,}{ }^{42}$ This has been ascribed to the surface poisoning by the precursor ligands that hinders the Pd nucleation step..$^{40}$

The particle size has been evaluated from the various SEM images and the size distributions are plotted, for each $N$, as insets on Figure 2. The average particle size $\left(D_{\mathrm{Pd}}\right)$ is then plotted in Figure 3. As expected $D_{\mathrm{Pd}}$ increases with $N$ since the growth of the existing particles occurs more likely than the nucleation of additional clusters on the oxidized surface. $D_{\mathrm{Pd}}$ varies from $6.5 \pm 1$ to $25 \pm 3 \mathrm{~nm}$ for $N$ ranging from 400 to 900 cycles. After an incubation time of approximately 600 cycles, $D_{\mathrm{Pd}}$ increases linearly. The growth rate, deduced from the slope between 700 and 900 cycles, is $0.7 \AA /$ cycle. It is notably higher than the growth rate of $0.21 \AA /$ cycle determined in a previous work ${ }^{39}$ by quartz crystal microbalance $(\mathrm{QCM})$ for Pd deposition onto $\mathrm{Al}_{2} \mathrm{O}_{3}$. This discrepancy can be explained because, in the present work, the rate corresponds to the average particle size while the growth rate given by Elam et al..$^{39}$ corresponds to the thickness evolution calculated from the QCM data for a homogeneous film. Nevertheless, the evolutions are in agreement and both depict the same deposition process, i. e., an incubation delay due to the oxidized nature of the substrate and an island growth mechanism.

In order to demonstrate the full coverage of the TNTs by the Pd, SEM and TEM cross sections have been performed on the nanotubes after ALD of Pd. Figure 4a shows a side view of the TNTs after Pd growth. It appears distinctly on the micrograph that the external walls of the tubes are completely coated by the metallic nanoparticles. It indicates that the Pd deposition even proceeds within the narrow interstitial voids.

During the sample cutting, it is unlikely that the nanotubes are sliced along their longitudinal axis. Hence, it is almost impossible to observe, by SEM, the inner coverage of the tubes by the 
Pd clusters. The TEM cross section presented in Figure $4 \mathrm{~b}$ reveals, conversely, the presence of Pd nanoparticles within the TNTs even at the bottom part of the tubes (see the arrows on Figure $4 \mathrm{~b})$. This demonstrates clearly that the ALD process uniformly and fully coats the TNTs.

Figure 5 shows TEM observations of Pd clusters deposited on the TNTs after 500 ALD cycles. A general view of a tube mouth decorated by Pd clusters is shown in Figure 5a. The underlying $\mathrm{TiO}_{2}$ is pointed out by the blue shadow. It confirms that the deposition occurs on both sides of the tube walls. The size distribution of the Pd particles is relatively homogeneous and the average size, around 7-8 $\mathrm{nm}$, is in the same range as the one observed, by SEM, on Figure 2. The high-resolution view of the deposit (Figure 5b) reveals the crystal planes of the particles and confirms crystalline nature of the Pd deposit. The particles look relatively homogeneous and are mainly single-crystalline. The selected area electron diffraction (SAED) carried out on the region is presented in Figure 5c. Numerous diffraction spots and rings are visible on the pattern. The diffraction rings are attributed to the Pd while the diffraction spots are ascribed to the anatase. It indicates that the amount of underlying $\mathrm{TiO}_{2}$ is very small. No preferential orientation is noticed in the table (shown in Supporting Information, S1) that lists the crystal planes detected by the SAED since all the main diffraction planes are visible for both materials.

Figure 6a displays the x-ray diffraction patterns of TNTs after Pd deposition for increasing number of cycles ( $N=300,400,500$ and 600 cycles). The peaks have been identified according to the reference databases (JCPDS \#046-1043, JCPDS \#044-1294). The diffraction peaks are mainly attributed to the $\mathrm{Ti}$ substrate and no $\mathrm{TiO}_{2}$ is detected since as-grown TNTs are amorphous. ${ }^{14}$ The diffraction peak located at $46.65^{\circ}$ can be attributed to the $\operatorname{Pd}(200)$ planes while the peak positioned around $40.1^{\circ}$ corresponds to the sum of $\operatorname{Pd}(111)$ and $\operatorname{Ti}(101)$ signals (40.12 and $40.17^{\circ}$, respectively). The evolution of the intensity of these peaks is presented in the insets 
(Figures $6 \mathrm{~b}$ and $6 \mathrm{c}$ ). In both cases, the linear increase with $N$ (see Supporting Information, S2) indicates that the Pd load is directly related to the number of cycles. The FWHM of the peaks decreases with the $N$. It qualitatively verifies the enlargement of particles observed previously on the SEM images. It is indeed not possible to use the Scherrer formula to evaluate the particle mean size because the main peak for Pd, the (111) plane, is located at the same diffraction angle of the $\operatorname{Ti}(101)$ and the intensity of the $\operatorname{Pd}(200)$ peak is too weak for a consistent quantitative analysis.

The surface composition of the Pd nanoparticles has been investigated by XPS. The characterizations were carried out on $\operatorname{Pd} / \mathrm{TNTs}(N=500$ cycles $)$ before and after the electrochemical measurements and the recorded peaks are shown in Figure 7. In the case of the as-prepared sample the deconvoluted Pd3d peak (Figure 7a, upper spectra) shows only one component at $335.4 \mathrm{eV}\left(\operatorname{Pd}_{3} \mathrm{~d}_{5 / 2}\right)$ that is attributed to $\mathrm{Pd}$ atoms in the metallic state. ${ }^{43}$ The analysis of the corresponding Ti2p (Figure $7 b$, upper spectra) shows the existence of a peak at $459.3 \mathrm{eV}$ characteristic of titanium atoms in the $4+$ oxidation state in $\mathrm{TiO}_{2}{ }^{36}$ The peak measured in the O1s region (Figure 7c, upper spectra) is the result of the overlapping of the O1s peak ascribed to $\mathrm{TiO}_{2}$ and the $\mathrm{Pd} 3 \mathrm{p}_{3 / 2}$. Thus, the two characteristic features of the peak at around 530.5 and $532.4 \mathrm{eV}$ are due to these two contributions, respectively. ${ }^{36,44}$

After the electrochemical studies a significant amount of potassium was detected on the surface as indicated by the intense $\mathrm{K} 2 \mathrm{p}$ peak that is detected around $293.5 \mathrm{eV}\left(\mathrm{K} 2 \mathrm{p}_{3 / 2}\right.$, not shown here). The deconvolution of the Pd3d peak (Figure 7a, lower spectra) reveals that beyond the component at lower BEs $\left(\mathrm{Pd}_{3} \mathrm{~d}_{5 / 2}: 335.1 \mathrm{eV}\right)$ due to metallic Pd, two additional peaks are present at higher BEs (336.1 and $337.2 \mathrm{eV}$ ). These two peaks are attributed to palladium in the $2+$ and 4+ oxidation states due to $\mathrm{PdO}$ and $\mathrm{PdO}_{2}$ and/or respective hydroxides. ${ }^{45-46} \mathrm{It}$ is therefore evident 
that after the electrochemical measurements, oxidation of palladium has taken place and around $40 \%$ of the detected signal is due to these oxygenated species. It should be mentioned that the signal of the Pd3d peak is almost one order of magnitude lower as compared to the signal of the as-prepared sample. This decrease is due to the presence of the potassium layer over Pd/TNTs sample, which is formed from the $\mathrm{KOH}$ electrolyte solution used during the ethanol electrooxidation measurements. The decrease of the Pd3d signal is accompanied by a steep decrease of Ti2p signal. More specifically, after ethanol electrooxidation, the Ti2p peak becomes rather ill defined (Figure $7 \mathrm{~b}$, lower spectra). At the same time, the $\mathrm{O} 1 \mathrm{~s}$ component at around $530.5 \mathrm{eV}$, which is attributed to the titanium dioxide, disappears. All these observations further support the fact that potassium covers the sample diminishing the signal of both Pd and TNT support. Nevertheless, the intensity of the peak detected in the $\mathrm{Pd} 3 \mathrm{p}_{3 / 2} / \mathrm{O} 1 \mathrm{~s}$ region for the sample after the electrochemical measurements does not show a respective decrease as it would be expected due to the potassium overlayer. Based on the fact that the second component of the $\mathrm{Pd} 3 \mathrm{p}$ doublet at around $560.2 \mathrm{eV}\left(\mathrm{Pd} 3 \mathrm{p}_{1 / 2}\right.$, not shown here) is of very low intensity and because the intensity ratio of the two components should be $2, I_{\mathrm{Pd} 3 \mathrm{p} 3 / 2}: I_{\mathrm{Pd} 3 \mathrm{p} 1 / 2}=2: 1,{ }^{43}$ we conclude that the relatively intense peak at around $532.5 \mathrm{eV}$ is not due to $\mathrm{Pd}$ but represents surface oxygen atoms that form palladium oxides and/or hydroxides after the electrochemical measurement. At this point we cannot exclude the formation of surface complexes that contain potassium as well. The $\mathrm{K} 2 \mathrm{p}_{3 / 2}$ is detected around $293.4 \mathrm{eV}$. In the literature this binding energy is reported for potassium atoms in ionic compounds ${ }^{43}$ and $\mathrm{K} / \mathrm{Pd}$. It is also well known that all alkali metals including potassium form oxopalladates $\left(\mathrm{K}_{\mathrm{n}} \mathrm{PdO}_{\mathrm{m}}\right){ }^{47}$ Further investigation is necessary to obtain a better insight of the K-based surface species. 
As mentioned before, as-grown TNTs are mainly amorphous. A phase transformation to anatase occurs after an annealing in air at $T=450^{\circ} \mathrm{C}$ for $2 \mathrm{~h}$. The anatase exhibits the highest electron conductivity and higher $\mathrm{O}^{2-}$ content..$^{48-49}$ It can therefore influence strongly the electroactivity of the supported Pd catalysts. In the following, the electrochemical response of the $\mathrm{Pd} / \mathrm{TNTs}$ systems has thus been investigated using either as-anodized or annealed nanotubes. Figure 8 presents the comparison of two Pd deposits carried out under the same ALD conditions ( $N=500$ cycles $)$ on as-grown and annealed nanotubes, respectively. The comparison of the SEM micrographs attests that there is no morphological difference between the two Pd films. Similarly, XPS and XRD investigations also confirm that neither chemical nor the crystalline variations are observed for the Pd deposit depending on the thermal treatment of the substrates. This allows a direct comparison of the electrocatalytic activity of Pd deposited on amorphous and on crystalline TNTs, as shown in the following section.

\section{Ethanol Electrooxidation}

Figure 9 shows cyclic voltammograms of Pd/TNTs samples containing 400, 500, 700 and 900 ALD cycles of Pd deposited on both as grown (solid line) and annealed (dashed line) TNTs in $1 \mathrm{M} \mathrm{KOH}$ (the reference CVs for bare TNTs are shown in Figure S3 in supporting information). For 400 ALD Pd/TNTs and samples with lower ALD cycles, the response of Pd is absent from the CVs. For samples of 500, 700 and 900 ALD cycles, the characteristic peaks of Pd oxidation and reduction as well as hydrogen evolution region are present on CVs. The absence of the Pd response for samples with low Pd loading, i. e., small clusters, could be a result of the SMSI effect in Pd/TNTs. SMSI is of either electronic or geometric type, latter also called decoration model..$^{9}{ }^{50}$ In the decoration model, the SMSI is a result of the back spillover of the partially reduced $\mathrm{TiO}_{x}$ species onto the surface of metal catalysts, which takes place when the catalyst is 
reduced in hydrogen at high temperature. As defined in the metal-semiconductor boundary layer theory, at thermodynamic equilibrium the Fermi energy level of electrons of the two materials in contact is equal. When two materials with different Fermi level (work function) put in contact, charge is transported from the material with the lower work function to the material with the higher work function. The work function of anatase $\mathrm{TiO}_{2}$ is $5.1 \mathrm{eV}^{51}$ and $\mathrm{Pd} 5.2-5.4 \mathrm{eV}$ for bulk Pd and even higher for nanoparticles. ${ }^{52-53}$ Upon contact the negative charge is transported from $\mathrm{TiO}_{2}$ to $\mathrm{Pd}$. Therefore, $\mathrm{O}^{2-}$ and/or $\mathrm{OH}^{-}$migration from $\mathrm{TiO}_{2}$ onto $\mathrm{Pd}$ surface is expected. In the "oxygen vacancy model" developed by Sanchez and Gasquez, ${ }^{54}$ the metal diffusion into support bulk vacancies and complete or partial burial of small metal crystallites were proposed. In addition, surface migration of $\mathrm{O}^{2-}$ and/or $\mathrm{OH}^{-}$can cover the metal clusters or strands bringing about complete elimination of sorptive and catalytic properties ${ }^{54}$ It is suggested that in the case of small $\mathrm{Pd}$ clusters, $\mathrm{Pd}$ atoms become buried into $\mathrm{TiO}_{2}$ support and covered by $\mathrm{O}^{2-} / \mathrm{OH}^{-}$, therefore fraction of accessible atoms is small and their sorptive and catalytic properties are affected negatively. As the particle size increases, the $\mathrm{Pd}-\mathrm{TiO}_{2}$ interaction diminishes and $\mathrm{Pd}$ atoms situated further from the support remain accessible to surrounding electrolyte and show similar CV profile as for bulk Pd electrode (Figure 9b-d). ${ }^{55}$ The anodic current growth at potentials more positive than $-0.2 \mathrm{~V}$ (Figure $9 \mathrm{~b}, 9 \mathrm{c}, 9 \mathrm{~d}$ ) is due to the formation of $\mathrm{Pd}-\mathrm{OH}, \mathrm{PdO}$ and $\mathrm{PdO}_{\mathrm{x}}$ that are developed successively as the potential becomes more positive. The cathodic peak centered at around $-0.2 \mathrm{~V}$ is due to the reduction of the Pd oxides formed on the anodic scan. The intensity of this peak depends on the maximum anodic potential, because a more complete oxide layer and higher valence oxides are formed at higher potentials. At potentials more negative than $-0.4 \mathrm{~V}$ the region of hydrogen adsorption/absorption and desorption is situated..$^{56}$ 
For Pd/TNTs with 500 ALD cycles, the current density is significantly higher for the annealed support confirming that the changes in $\mathrm{TiO}_{2}$ properties have a greater effect on smaller $\mathrm{Pd}$ clusters of lower loading (shown in Figure 2) than larger Pd deposits obtained at 700 and 900 ALD cycles. The annealing of $\mathrm{TiO}_{2}$ nanotubes in air at $450^{\circ} \mathrm{C}$ results in anatase structure with high conductivity. ${ }^{57}$ For samples containing 700 and 900 ALD cycles, the current densities are comparable for as-grown and annealed samples (Figure $9 \mathrm{c}$,d), but much lower than for 500 ALD. As was shown previously for Pt deposited on $\mathrm{TiO}_{2}$ nanotubes, ${ }^{58-59}$ the increase of the $\mathrm{Pt}$ amount led to the decrease of MSI effect, therefore affecting the catalytic properties of Pt to a lesser degree. The similar effect could be in play for Pd/TNTs of 700 and 900 ALD cycles. Furthermore, as the cluster size increases to 900 ALD cycles the current density decreases significantly if compared to Pd/TNTs of 700 and 500 ALD cycles. It can be also seen (Figure 9c) that annealing of the support not only affects the current values but also the ease of $\operatorname{PdO}_{x}$ formation and reduction. For instance, after annealing the peak of Pd oxidation decreases and shifts to higher anodic potentials, indicating that annealed-TNTs stabilize Pd in the metallic state, as also seen in the positive shift of $\mathrm{PdO}_{\mathrm{x}}$ reduction peak confirming that this process is more thermodynamically favorable on the annealed Pd/TNTs with 700 ALD cycles. In an earlier work, ${ }^{15} \mathrm{Pd}$ reduction peak was observed between 0.6 and $0.7 \mathrm{~V}$ vs RHE $(-0.341$ and $-0.241 \mathrm{~V}$ vs $\mathrm{Hg} / \mathrm{HgO}$ ) on $\mathrm{Pd}$ nanoparticles prepared by electrochemical milling of the larger Pd clusters. In another report, ${ }^{17}$ the reduction peak maximum was situated at $-0.45 \mathrm{~V}$ vs SCE $(-0.307 \mathrm{~V}$ vs. $\mathrm{Hg} / \mathrm{HgO}$ ). The reported potentials are more negative that ones observed in the present work indicating that charge transfer between $\mathrm{Pd}$ and TNTs and/or Pd interaction with $\mathrm{O}^{2-}$ bulk vacancies make the reduction of Pd oxides easier. 
Figure 10 compares electrocatalytic activity of the two catalysts with the same Pd loading (i.e., $N=500$ cycles) but deposited on as-grown and annealed TNTs for ethanol electrooxidation. The current density is much higher for Pd catalysts deposited on the annealed support and increases in the whole range of the anodic potentials, whereas for as-grown Pd/TNTs system, the maximum current density is reached at $0.15 \mathrm{~V}$ following by the catalyst deactivation due to oxide formation. The increase in the current density for annealed TNTs is due to the increased conductivity of the anatase structured $\mathrm{TiO}_{2}$ nanotubes over the amorphous $\mathrm{TiO}_{2}$ nanotubes..$^{60}$ Therefore, the further studies of the effect of Pd loading were carried out on annealed TNTs.

The three Pd/TNTs catalysts with 500, 700 and 900 ALD cycles were tested for ethanol electrooxidation and the resulting cyclic voltammograms are shown in Figure 11. The current densities are given per geometric area and ECSA on Figure 11a and 11b, respectively. As the number of ALD cycles increases the particle size increases as shown in Figure 2 and confirmed by XRD measurements, which in turn will influence the available active surface area. Therefore, in order to compare the intrinsic activity of Pd/TNTs prepared with different number of ALD cycles, the ECSA of Pd/TNTs catalysts was estimated using $\mathrm{PdO}$ reduction peak in $\mathrm{H}_{2} \mathrm{SO}_{4}{ }^{61}$ (Figure S4 in supporting information). The distinct PdO reduction peak in acid media makes the calculation of the charge required to oxidize the monolayer of PdO more straightforward and accurate than in alkaline media. ${ }^{61}$ It is accepted that the reduction charge of a full monolayer of Pd monoxide is $420 \mu \mathrm{C} \mathrm{cm}^{-2}{ }^{62-65}$ The formation of Pd oxide at a fixed cathodic potential is a function of time and the $\mathrm{PdO}$ reduction charge reaches the plateau in the region where a complete $\mathrm{PdO}$ monolayer is formed.$^{65}$ The estimated ECSA, for Pd deposited on annealed $\mathrm{TiO}_{2}$ nanotubes with 500, 700 and 900 ALD cycles is $22.3,29.6$ and $7.1 \mathrm{~cm}^{2}$, respectively. The ECSA 
increases as number of cycle increases from 500 to 700 . At the same time, the average nanoparticle size increases as well from 7 till $11 \mathrm{~nm}$ indicating that ECSA increase is not purely geometric but an interaction with $\mathrm{TiO}_{2}$ support and formation of new active sites probably occur. Furthermore, the particle distribution and interparticle distance have larger contribution towards ECSA than Pd particle size on its own. The significant decrease of ECSA for 900 ALD cycles is due to the formation of the larger coalesced Pd clusters with lower surface area (average size of $25 \mathrm{~nm}$, Figure 2) and/or partial obstruction of the 3D nanostructure of TNTs by large Pd clusters.

Figure 11 shows that when current density is normalized by geometric area, its amplitude for 500 and 700 ALD cycles is the same up to $0.3 \mathrm{~V}$, where the sample covered by 700 cycles deactivates rapidly due to Pd oxidation, while the current density continues to increase up to $0.36 \mathrm{~V}$ for $N=500$ cycles $\mathrm{On}$ the reverse scan all three catalyst remain inactive till $-0.15 \mathrm{~V}$, because more negative potentials are required to reduce $\mathrm{PdO}_{x}$, which is not a catalyst for ethanol electrooxidation.

The comparison of the intrinsic activity of the three Pd/TNTs catalysts (Figure 11b) shows that the sample covered by 500 cycles Pd exhibits the highest current density in the entire potential region in both forward and backward scans, also it remains active till higher potentials if compare to two other catalysts. The catalyst with 900 ALD cycles has a much lower activity due to the larger particle size and partial closing of the TNTs. In order to compare the present results with literature, the Pd load (i. e. the mass of Pd, $m_{\mathrm{Pd}}$, per area unit) has been estimated from the ECSA and the $D_{\mathrm{Pd}}$. Using these two experimental measurements, it has been possible to estimate the particle density $\left(N_{\mathrm{Pd}}\right)$ and $m_{\mathrm{Pd}}$. The $m_{\mathrm{Pd}}$ is 31,76 and $35 \mu \mathrm{g} \cdot \mathrm{cm}^{-2}$, for a number of 500,700 and 900 ALD cycles, respectively. The $m_{\mathrm{Pd}}$ for 500 and 700 ALD cycles appear realistic. However, the low value for 900 ALD cycles shows, of course, the limitation of the calculation when the 
particles merge (since the ECSA is a superficial measurement it cannot be used to calculate accurately the mass of a continuous Pd film). Nevertheless, the $m_{\mathrm{Pd}}$ for 500 ALD is the most interesting for comparisons since it exhibits the highest activity. The peak current for ethanol oxidation is approximately $2.25 \mathrm{~A} \mathrm{mg}^{-1}$ for 500 ALD cycles. The comparison of this electroactivity with literature is thus promising. Qin et al. ${ }^{17}$ reported for Pd deposited into TNTs an oxidation current of ca. $6 \mathrm{~A} \mathrm{mg}^{-1}$ with $\mathrm{CVs}$ performed at a higher scan rate $\left(50 \mathrm{mV} \mathrm{s}^{-1}\right)$. Similarly, Chen et al. ${ }^{15}$ have measured an oxidation current of ca. $9 \mathrm{~A} \mathrm{mg}^{-1}$ but the experiments were carried out in a more concentrated solution $\left(c_{\text {ethanol }}=2.2 \mathrm{~mol} \mathrm{~L}^{-1}\right)$ and the scan rate was also two times higher $\left(50 \mathrm{mV} \mathrm{s}^{-1}\right)$. The comparison with Pd catalysts deposited by ALD on porous carbon is even more promising. Rikkinen et al..$^{32}$ have indeed reported an electroactivity 4.5 times higher than commercial materials, but the oxidation current remains four times lower than the present study with a current of $0.5 \mathrm{~A} \mathrm{mg}^{-1}$ at $0.75 \mathrm{~V}$ vs. RHE. ${ }^{32}$

Figure 12 shows chronoamperograms of Pd catalysts with various loading deposited on annealed TNTs at $-0.2 \mathrm{~V}$. For the sample with 900 ALD cycles, the current density starts at $0.13 \mathrm{~mA} \mathrm{~cm}^{-2}$ and diminishes very fast until it reaches a steady-state at about $0.03 \mathrm{~mA} \mathrm{~cm}{ }^{-2}$. The samples with 500 and 700 cycles show higher initial current density values of 0.25 and $0.20 \mathrm{~mA} \mathrm{~cm}^{-2}$, respectively, however the current density continues to decrease without reaching a steady-state even after $1 \mathrm{~h}$. The current decrease is due to poisoning of the Pd surface active sites by adsorbed ethoxy $\left(\mathrm{CH}_{3} \mathrm{CH}_{2} \mathrm{O}\right)$ or other poisonous (C2) intermediates., ${ }^{8} 66$ The decay could be also associated with $\mathrm{PdO}_{x}$ formation, confirmed by the XPS measurements of the $\mathrm{Pd} / \mathrm{TNTs}$ after ethanol electrooxidation (Figure 7). XPS showed that palladium in the $2+$ and $4+$ oxidation states was formed. In addition, as shown by XPS, the formation of oxopalladate $\left(\mathrm{K}_{n} \mathrm{PdO}_{\mathrm{m}}\right)$ complexes cannot be ruled out. Therefore, the above effects would gradually decrease the 
number of active sites and lead to the continuous current decay. The current percentage loss, after double layer correction, is $71.6,57.3$ and $40.1 \%$ for 500, 700 and 900 ALD of Pd, respectively.

CA measurements showed that the samples with 500 and 700 cycles are more active, at least during the first hours of operation, while the sample with 900 cycles shows a much lower catalytic activity under the same operating conditions but it reaches quickly (after $1500 \mathrm{~s}$ ) a steady-state around $0.03 \mathrm{~mA} \mathrm{~cm}^{-2}$. The levels of the current densities are in agreement with CVs experiments shown in Figure 11b (where a vertical dashed line indicate the potential corresponding to the CA experiments).

The electrochemical measurements showed that Pd deposited using 500 ALD cycles (average particle size of $6.5 \mathrm{~nm}$ ) on annealed TNTs has the optimum electrocatalytic performance. For samples with lower ALD cycles, no electrochemical response was detected for both annealed and as-grown samples. It is proposed that SMSI results in the coverage and/or burial of small Pd clusters into $\mathrm{TiO}_{2}$ nanotubes. This effectively negated sorptive and catalytic properties of $\mathrm{Pd}$ deposited using 400 and fewer ALD cycles. For Pd/TNTs electrocatalysts of 700 and 900 ALD cycles, it is suggested that both larger particle size, implying the lower active surface area, as well as weaker electronic interaction between $\mathrm{Pd}$ clusters and $\mathrm{TiO}_{2}$ nanotubes was responsible for lower catalytic activity.

\section{Conclusion}

In the present work we show that ALD can be successfully used to functionalize TNTs with Pd nanoparticles for ethanol electrooxidation. The particle size is precisely controlled by the number of ALD cycles and the catalysts fully cover the inner and outer walls of the nanotubes. ALD allows the use of a controlled amount of Pd and can thus decrease the costs. The influence of the 
substrate on the catalyst activity has been demonstrated trough the modification of the crystalline structure of the TNTs. The electrooxidation of ethanol is indeed strongly enhanced when the $\mathrm{TiO}_{2}$ is annealed since anatase is more conductive than the amorphous $\mathrm{TiO}_{2}$. Catalysts with the different number of ALD cycles were prepared. It was found by SEM and XRD that Pd forms well-defined and crystalline nanoparticles with face-centred cubic (fcc) structure on entire surface of TNTs. The particle and crystallite size increases with the number of ALD cycles. XPS analysis showed that as prepared Pd nanoparticles are present in metallic state, whereas after ethanol electrooxidation $40 \%$ of surface $\mathrm{Pd}$ is transformed to $\mathrm{PdO}_{\mathrm{x}}$. Among the prepared electrocatalysts $(N=400-900$ ALD cycles), the 500 ALD Pd/TNTs system showed the best catalytic activity and satisfactory stability in alkaline media. The electrochemical characterizations have demonstrated that these Pd/TNTs systems exhibit high current densities and low onset potential if compared to the literature and commercial catalysts. The use of ALD to grow metallic nanoparticles onto three-dimensional nanostructured substrates appears to be a very promising approach for preparation of well-defined catalysts for ethanol and other alcohol electrooxidation.

\section{ASSOCIATED CONTENT}

Supporting Information. Indexing of the selected area electron diffraction for Pd nanoparticles deposited on TNTs. Evolution of the diffraction peaks $\left(2 \theta=40.1^{\circ}\right.$ and $\left.46.5^{\circ}\right)$ with $N$. Electrochemical behavior of the bare TNTs. Cyclic voltammetry of $\mathrm{Pd} / \mathrm{TNT}$ in $0.5 \mathrm{M} \mathrm{H}_{2} \mathrm{SO}_{4}$ used for ECSA estimation. This material is available free of charge via the Internet at http://pubs.acs.org.

\section{AUTHOR INFORMATION}




\section{Corresponding Author}

*To whom correspondence should be addressed: elena.baranova@uottawa.ca;

lionel.santinacci@univ-amu.fr

\section{Present Addresses}

$\S$ Université Paris Sud - CNRS, Institut de Chimie Moléculaire et des Matériaux d'Orsay, Rue du Doyen Georges Poitou, F-91405 Orsay, France.

\section{Author Contributions}

The manuscript was written through contributions of all authors.

${ }^{\perp}$ These authors contributed equally.

\section{ACKNOWLEDGMENT}

The authors acknowledge D. Chaudanson, S. Nitsche (CINaM) and Y. Yamamoto (JEOL France for the SEM pictures obtained with the JEOL 7800F) for their precious help with the electron microscopy and V. Heresanu (CINaM) for XRD measurements and interpretation. A. Baronnet $(\mathrm{CINaM})$ is also acknowledged for fruitful discussions. This collaborative work was supported by the France-Canada Research Fund. M. K. S. Barr and L. Assaud are indebted to the Conseil Régional Provence-Alpes-Côte d'Azur and the CNRS for the PhD grants.

\section{REFERENCES}

(1) Bianchini, C.; Shen, P. K., Palladium-Based Electrocatalysts for Alcohol Oxidation in Half Cells and in Direct Alcohol Fuel Cells. Chem. Rev. 2009, 109, 4183-4206.

(2) Antolini, E., Catalysts for Direct Ethanol Fuel Cells. J. Power Sources 2007, 170, 1-12. 
(3) Dillon, R.; Srinivasan, S.; Arico, A.; Antonucci, V., International Activities in Dmfc R\&D: Status of Technologies and Potential Applications. J. Power Sources 2004, 127, 112-126.

(4) Antolini, E., Palladium in Fuel Cell Catalysis. Energy Environ. Sci. 2009, 2, 915-931.

(5) Bambagioni, V.; Bianchini, C.; Marchionni, A.; Filippi, J.; Vizza, F.; Teddy, J.; Serp, P.; Zhiani, M., Pd and Pt-Ru Anode Electrocatalysts Supported on Multi-Walled Carbon Nanotubes and Their Use in Passive and Active Direct Alcohol Fuel Cells with an Anion-Exchange Membrane (Alcohol = Methanol, Ethanol, Glycerol). J. Power Sources 2009, 190, 241-251.

(6) Feng, Y.-Y.; Liu, Z.-H.; Xu, Y.; Wang, P.; Wang, W.-H.; Kong, D.-S., Highly Active Pdau Alloy Catalysts for Ethanol Electro-Oxidation. J. Power Sources 2013, 232, 99-105.

(7) Monyoncho, E. A.; Ntais, S.; Soares, F.; Woo, T. K.; Baranova, E. A., Synergetic Effect of Palladium-Ruthenium Nanostructures for Ethanol Electrooxidation in Alkaline Media. $J$. Power Sources 2015, 287, 139-149.

(8) Neto, A. O.; da Silva, S. G.; Buzzo, G. S.; de Souza, R. F. B.; Assumpção, M. H. M. T.; Spinacé, E. V.; Silva, J. C. M., Ethanol Electrooxidation on Pdir/C Electrocatalysts in Alkaline Media: Electrochemical and Fuel Cell Studies. Ionics 2015, 21, 487-495.

(9) Tauster, S. J.; Fung, S. C.; Garten, R. L., Strong Metal-Support Interactions - Group-8 Noble-Metals Supported on $\mathrm{Tio}_{2}$. J. Am. Chem. Soc. 1978, 100, 170-175.

(10) Hepel, M.; Kumarihamy, I.; Zhong, C. J., Nanoporous Tio2-Supported Bimetallic Catalysts for Methanol Oxidation in Acidic Media. Electrochem. Commun. 2006, 8, 1439-1444. 
(11) Ntais, S.; Isaifan, R. J.; Baranova, E. A., An X-Ray Photoelectron Spectroscopy Study of Platinum Nanoparticles on Yttria-Stabilized Zirconia Ionic Support: Insight into Metal Support Interaction. Mater. Chem. Phys. 2014, 148, 673-679.

(12) Zhang, J.; Cheng, Y.; Lu, S.; Jia, L.; Shen, P. K.; Jiang, S. P., Significant Promotion Effect of Carbon Nanotubes on the Electrocatalytic Activity of Supported Pd Nps for Ethanol Oxidation Reaction of Fuel Cells: The Role of Inner Tubes. Chem. Commun. 2014, 50, 1373213734.

(13) Huang, S.-Y.; Ganesan, P.; Park, S.; Popov, B. N., Development of a Titanium DioxideSupported Platinum Catalyst with Ultrahigh Stability for Polymer Electrolyte Membrane Fuel Cell Applications. J. Am. Chem. Soc. 2009, 131, 13898-13899.

(14) Lee, K.; Mazare, A.; Schmuki, P., One-Dimensional Titanium Dioxide Nanomaterials: Nanotubes. Chem. Rev. 2014, 114, 9385-9454.

(15) Chen, Y.-X.; Lavacchi, A.; Chen, S.-P.; di Benedetto, F.; Bevilacqua, M.; Bianchini, C.; Fornasiero, P.; Innocenti, M.; Marelli, M.; Oberhauser, W.; Sun, S.-G.; Vizza, F., Electrochemical Milling and Faceting: Size Reduction and Catalytic Activation of Palladium Nanoparticles. Angew. Chem. Int. Ed. 2012, 51, 8500-8504.

(16) Xu, W.; Zhu, S.; Li, Z.; Cui, Z.; Yang, X., Synthesis and Catalytic Properties of Pd Nanoparticles Loaded Nanoporous Tio2 Material. Electrochim. Acta 2013, 114, 35-41.

(17) Qin, Y.-H.; Yang, H.-H.; Lv, R.-L.; Wang, W.-G.; Wang, C.-W., Tio2 Nanotube Arrays Supported Pd Nanoparticles for Ethanol Electrooxidation in Alkaline Media. Electrochim. Acta 2013, 106, 372-377. 
(18) Elam, J. W.; Routkevitch, D.; Mardilovich, P. P.; George, S. M., Conformal Coating on Ultrahigh-Aspect-Ratio Nanopores of Anodic Alumina by Atomic Layer Deposition. Chem. Mater. 2003, 15, 3507-3517.

(19) Hausmann, D.; Becker, J.; Wang, S.; Gordon, R. G., Rapid Vapor Deposition of Highly Conformal Silica Nanolaminates. Science 2002, 298, 402-406.

(20) Moyen, E.; Santinacci, L.; Masson, L.; Wulfhekel, W.; Hanbücken, M., A Novel SelfOrdered Sub-10 Nm Nanopore Template for Nanotechnology. Adv. Mater. 2012, 24, 5094-5098.

(21) Detavernier, C.; Dendooven, J.; Sree, S. P.; Ludwig, K. F.; Martens, J. A., Tailoring Nanoporous Materials by Atomic Layer Deposition. Chem. Soc. Rev. 2011, 40, 5242-5253.

(22) Elam, J. W.; Dasgupta, N. P.; Prinz, F. B., Ald for Clean Energy Conversion, Utilization, and Storage. MRS Bull. 2011, 36, 899-906.

(23) Lu, J.; Elam, J. W.; Stair, P. C., Synthesis and Stabilization of Supported Metal Catalysts by Atomic Layer Deposition. Acc. Chem. Res. 2013, 46, 1806-1815.

(24) Goldstein, D. N.; George, S. M., Enhancing the Nucleation of Palladium Atomic Layer Deposition on A12o3 Using Trimethylaluminum to Prevent Surface Poisoning by Reaction Products. Appl. Phys. Lett. 2009, 95, 143106.

(25) Assaud, L.; Schumacher, J.; Tafel, A.; Bochmann, S.; Christiansen, S.; Bachmann, J., Systematic Increase of Electrocatalytic Turnover at Nanoporous Platinum Surfaces Prepared by Atomic Layer Deposition. J. Mater. Chem. A 2015, 3, 8450-8458. 
(26) Feng, H.; Libera, J. A.; Stair, P. C.; Miller, J. T.; Elam, J. W., Subnanometer Palladium Particles Synthesized by Atomic Layer Deposition. ACS Catal. 2011, 1, 665-673.

(27) Lu, J.; Liu, B.; Greeley, J. P.; Feng, Z.; Libera, J. A.; Lei, Y.; Bedzyk, M. J.; Stair, P. C.; Elam, J. W., Porous Alumina Protective Coatings on Palladium Nanoparticles by Self-Poisoned Atomic Layer Deposition. Chem. Mater. 2012, 24, 2047-2055.

(28) Su, C.-Y.; Hsueh, Y.-C.; Kei, C.-C.; Lin, C.-T.; Perng, T.-P., Fabrication of HighActivity Hybrid Pt@Zno Catalyst on Carbon Cloth by Atomic Layer Deposition for Photoassisted Electro-Oxidation of Methanol. J. Phys. Chem.C 2013, 117, 11610-11618.

(29) Jukk, K.; Kongi, N.; Tarre, A.; Rosental, A.; Treshchalov, A. B.; Kozlova, J.; Ritslaid, P.; Matisen, L.; Sammelselg, V.; Tammeveski, K., Electrochemical Oxygen Reduction Behaviour of Platinum Nanoparticles Supported on Multi-Walled Carbon Nanotube/Titanium Dioxide Composites. J. Electroanal. Chem. 2014, 735, 68-76.

(30) Chih-Chieh, W.; Yang-Chih, H.; Chung-Yi, S.; Chi-Chung, K.; Tsong-Pyng, P., Deposition of Uniform Pt Nanoparticles with Controllable Size on Tio 2 -Based Nanowires by Atomic Layer Deposition and Their Photocatalytic Properties. Nanotechnology 2015, 26, 254002.

(31) Feng, H.; Elam, J. W.; Libera, J. A.; Setthapun, W.; Stair, P. C., Palladium Catalysts Synthesized by Atomic Layer Deposition for Methanol Decomposition. Chem. Mater. 2010, 22, $3133-3142$.

(32) Rikkinen, E.; Santasalo-Aarnio, A.; Airaksinen, S.; Borghei, M.; Viitanen, V.; Sainio, J.; Kauppinen, E. I.; Kallio, T.; Krause, A. O. I., Atomic Layer Deposition Preparation of Pd 
Nanoparticles on a Porous Carbon Support for Alcohol Oxidation. J. Phys. Chem. C 2011, 115, 23067-23073.

(33) Assaud, L.; Monyoncho, E.; Pitzschel, K.; Allagui, A.; Petit, M.; Hanbuecken, M.; Baranova, E. A.; Santinacci, L., 3d-Nanoarchitectured Pd/Ni Catalysts Prepared by Atomic Layer Deposition for the Electrooxidation of Formic Acid. Beilstein J. Nanotechnol. 2014, 5, $162-172$.

(34) Richter, K.; Peplinski, B., Energy Calibration of Electron Spectrometers. J. Electron. Spectrosc. Relat. Phenom. 1978, 13, 69-71.

(35) Hüfner, S.; Wertheim, G. K., Core-Line Asymmetries in the X-Ray-Photoemission Spectra of Metals. Phys. Rev. B 1975, 11, 678-683.

(36) Ntais, S.; Dracopoulos, V.; Siokou, A., $\operatorname{Ticl}_{4}\left(\mathrm{Thf}_{2}\right)_{2}$ Impregnation on a Flat $\mathrm{Sio}_{x} / \mathrm{Si}(100)$ and on Polycrystalline Au Foil: Determination of Surface Species Using Xps. J. Mol. Catal. A: Chem. 2004, 220, 199-205.

(37) Czerwinski, A., The Adsorption of Carbon Oxideson a Palladium Electrode from Acidic Solution J. Electroanal. Chem. 1994, 379, 487-493.

(38) Assaud, L.; Heresanu, V.; Hanbuecken, M.; Santinacci, L., Fabrication of P/N Heterojunctions by Electrochemical Deposition of $\mathrm{Cu}_{2} \mathrm{O}$ onto Tio2 Nanotubes. C. R. Chim. 2013, $16,89-95$.

(39) Elam, J. W.; Zinovev, A.; Han, C. Y.; Wang, H. H.; Welp, U.; Hryn, J. N.; Pellin, M. J., Atomic Layer Deposition of Palladium Films on Al2o3 Surfaces. Thin Solid Films 2006, 515, $1664-1673$. 
(40) Goldstein, D. N.; George, S. M., Surface Poisoning in the Nucleation and Growth of Palladium Atomic Layer Deposition with Pd(Hfac)2 and Formalin. Thin Solid Films 2011, 519, $5339-5347$.

(41) Campbell, C. T., Ultrathin Metal Films and Particles on Oxide Surfaces: Structural, Electronic and Chemisorptive Properties. Surf. Sci.Rep. 1997, 27, 1-111.

(42) Weber, M. J.; Mackus, A. J. M.; Verheijen, M. A.; van der Marel, C.; Kessels, W. M. M., Supported Core/Shell Bimetallic Nanoparticles Synthesis by Atomic Layer Deposition. Chem. Mater. 2012, 24, 2973-2977.

(43) Briggs, D.; Seah, M. P., Auger and X-Ray Photoelectron Spectroscopy. In Practical Surface Analysis 2nd ed.; Briggs, D.; Seah, M. P., Eds. John Wiley \& Sons: New York, 1996.

(44) Militello, M. C.; Simko, S. J., Elemental Palladium by Xps. Surf. Sci. Spectra 1994, 3, 387-394.

(45) Shafeev, G. A.; Themlin, J. M.; Bellard, L.; Marine, W.; Cros, A., Enhanced Adherence of Area-Selective Electroless Metal Plating on Insulators. J. Vac. Sci. Technol. A 1996, 14, 319326.

(46) Gao, W.; Jin, R.; Chen, J.; Guan, X.; Zeng, H.; Zhang, F.; Liu, Z.; Guan, N., TitaniaSupported Pd-Cu Bimetallic Catalyst for the Reduction of Nitrite Ions in Drinking Water. Catal. Lett. 2003, 91, 25-30.

(47) Griffith, W. P.; Robinson, S. D.; Swars, K., Palladium. In Gmelin Handbook of Inorganic Chemistry, 8th ed.; Griffith, W. P.; Swars, K., Eds. Springer-Verlag GmbH: Berlin Heidelberg 1989. 
(48) Tang, H.; Prasad, K.; Sanjinès, R.; Schmid, P. E.; Lévy, F., Electrical and Optical Properties of Tio2 Anatase Thin Films. J. App. Phys. 1994, 75, 2042.

(49) Tighineanu, A.; Albu, S. P., Conductivity of Anodic $\mathrm{Tio}_{2}$ Nanotubes: Influence of Annealing Conditions. Phys. Status Solidi RRL 2014, 8, 158-162.

(50) Haller, G. L.; Resasco, D. E., Metal-Support Interaction: Group Viii Metals and Reducible Oxides. Adv. Catal. 1989, 36, 173-235.

(51) Xiong, G.; Shao, R.; Droubay, T. C.; Joly, A. G.; Beck, K. M.; Chambers, S. A.; Hess, W. P., Photoemission Electron Microscopy of $\mathrm{Tio}_{2}$ Anatase Films Embedded with Rutile Nanocrystals. Adv. Funct. Mater. 2007, 17, 2133-2138.

(52) Singh-Miller, N. E.; Marzari, N., Surface Energies, Work Functions, and Surface Relaxations of Low-Index Metallic Surfaces from First Principles. Phys. Rev. B 2009, 80, 235407.

(53) Harinipriya, S.; Sangaranarayanan, M. V., Influence of the Work Function on Electron Transfer Processes at Metals: Application to the Hydrogen Evolution Reaction. Langmuir 2002, $18,5572-5578$.

(54) Sanchez, M. G.; Gazquez, J. L., Oxygen Vacancy Model in Strong Metal-Support Interaction. J. Catal. 1987, 104, 120-135.

(55) Burke, L. D.; Casey, J. K., The Electrocatalytic Behaviour of Palladium in Acid and Base. J. Appl. Electrochem. 1993, 23, 573-582. 
(56) Ruvinsky, P. S.; Pronkin, S. N.; Zaikovskii, V. I.; Bernhardt, P.; Savinova, E. R., On the Enhanced Electrocatalytic Activity of Pd Overlayers on Carbon-Supported Gold Particles in Hydrogen Electrooxidation. Phys. Chem. Chem. Phys. 2008, 10, 6665-6676.

(57) Stiller, M.; Barzola-Quiquia, J.; Lorite, I.; Esquinazi, P.; Kirchgeorg, R.; Albu, S. P.; Schmuki, P., Transport Properties of Single Tio ${ }_{2}$ Nanotubes. Appl. Phys. Lett. 2013, 103, 173108.

(58) Rettew, R. E.; Allam, N. K.; Alamgir, F. M., Interface Architecture Determined Electrocatalytic Activity of Pt on Vertically Oriented Tio2 Nanotubes. ACS Appl. Mater. Interfaces 2011, 3, 147-151.

(59) Cheng, S.; Rettew, R. E.; Sauerbrey, M.; Alamgir, F. M., Architecture-Dependent Surface Chemistry for Pt Monolayers on Carbon-Supported Au. ACS Appl. Mater. Interfaces 2011, 3, 3948-3956.

(60) Tighineanu, A.; Ruff, T.; Albu, S.; Hahn, R.; Schmuki, P., Conductivity of Tio2 Nanotubes: Influence of Annealing Time and Temperature. Chem. Phys. Lett. 2010, 494, 260263.

(61) Horkans, J., The Hydrogen Region of the Cyclic Voltammetry of Pd: The Effect of the Ph and Anion. J. Electroanal. Chem. 1986, 209, 371-376.

(62) Chierchie, T.; Mayer, C.; Lorenz, W. J., Structural Changes of Surface Oxide Layers on Palladium J. Electroanal. Chem. 1982, 135, 211-220.

(63) Correia, A. N.; Mascaro, L. H.; Machado, S. A. S.; Avaca, L. A., Active Surface Area Determination of Pd-Si Alloys by H-Adsorption. Electrochim. Acta 1997, 42, 493-495. 
(64) Juodkazis, K.; Juodkazyte, J.; Sebeka, B.; Sukienë, V., Kinetic Regularities of Cathodic Reduction of Palladium (Ii) Oxide Surface Layer. Chemija 2003, 14, 78.

(65) Rand, D. A. J.; Woods, R., The Nature of Adsorbed Oxygen on Rhodium, Palladium and Gold Electrodes. J. Electroanal. Chem. 1971, 31, 29-38.

(66) Yang, Y.-Y.; Ren, J.; Li, Q.-X.; Zhou, Z.-Y.; Sun, S.-G.; Cai, W.-B., Electrocatalysis of Ethanol on a Pd Electrode in Alkaline Media: An in Situ Attenuated Total Reflection SurfaceEnhanced Infrared Absorption Spectroscopy Study. ACS Catal. 2014, 4, 798-803. 


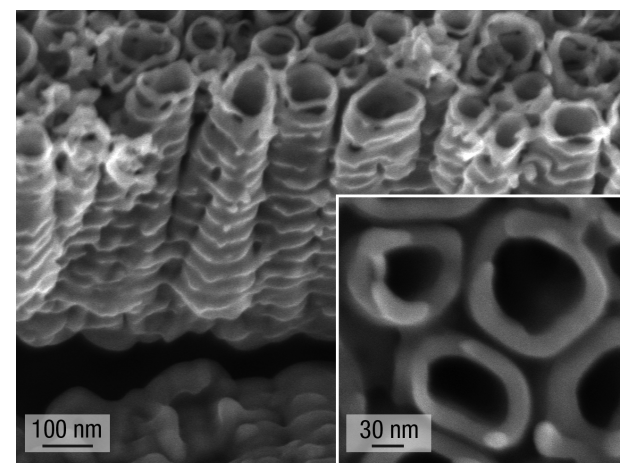

Figure 1. SEM image of TNTs grown at $U=20 \mathrm{~V}$ for $1 \mathrm{~h}$ in $1 \mathrm{M} \mathrm{H}_{3} \mathrm{PO}_{4}+1 \mathrm{M} \mathrm{NaOH}+$ $0.5 \% \mathrm{HF}$. The inset shows a high-magnification top view of the tubes mouth. 


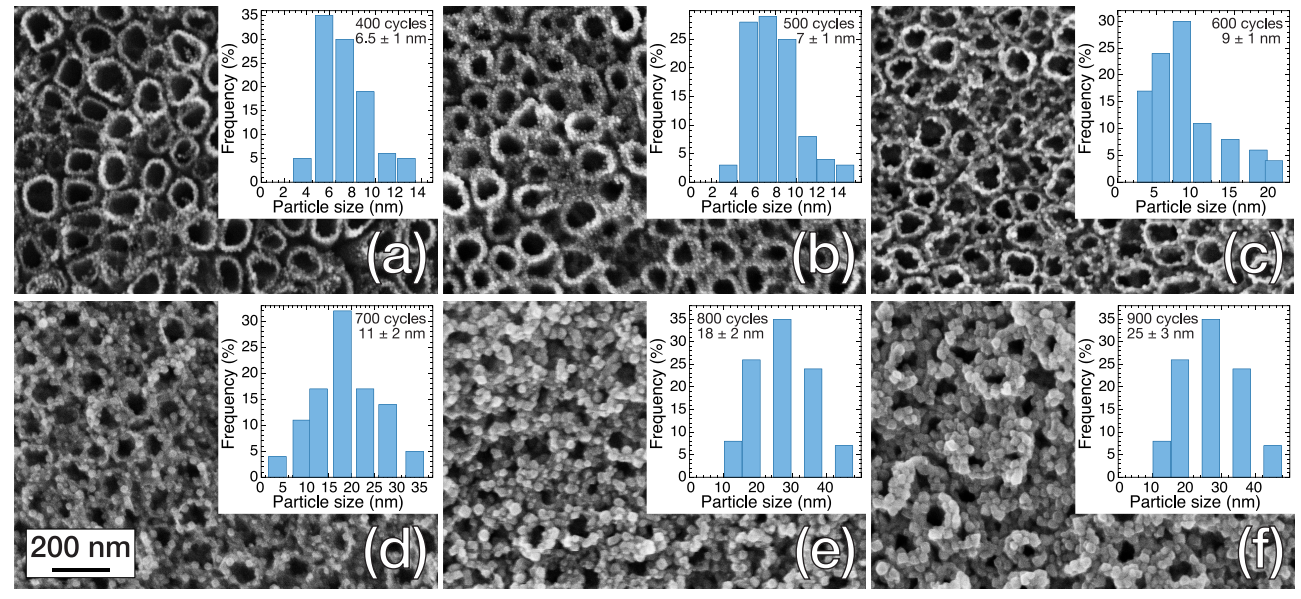

Figure 2. SEM micrographs of TNTs coated by Pd nanoparticles with increasing number of ALD cycles: (a) 400, (b) 500, (c) 600, (d) 700, (e) 800, and (f) 900 cycles. Insets show the size distribution estimated, for each $N$, from the SEM pictures. 


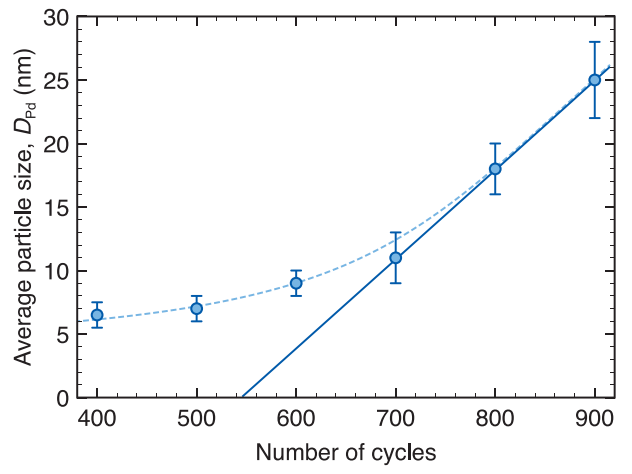

Figure 3. Evolution of the average size of Pd particles with the number of ALD cycles. 

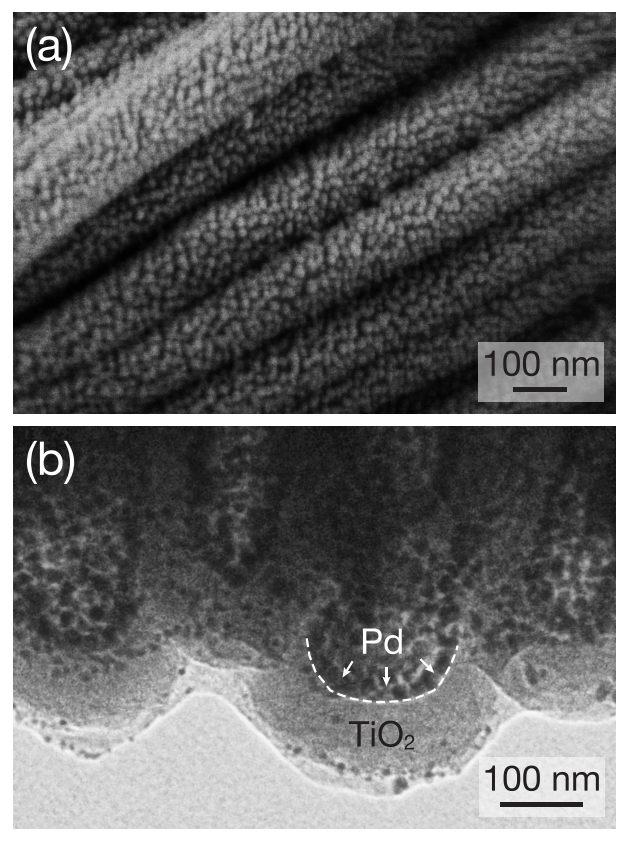

Figure 4. (a) SEM side view showing the external wall of TNTs covered by Pd nanoparticles. (b) TEM cross section of the bottom part of the TNTs after Pd deposition. The dashed line highlights the bottom part of one nanotube covered by Pd nanoparticles. $N=700$ cycles in both cases. 

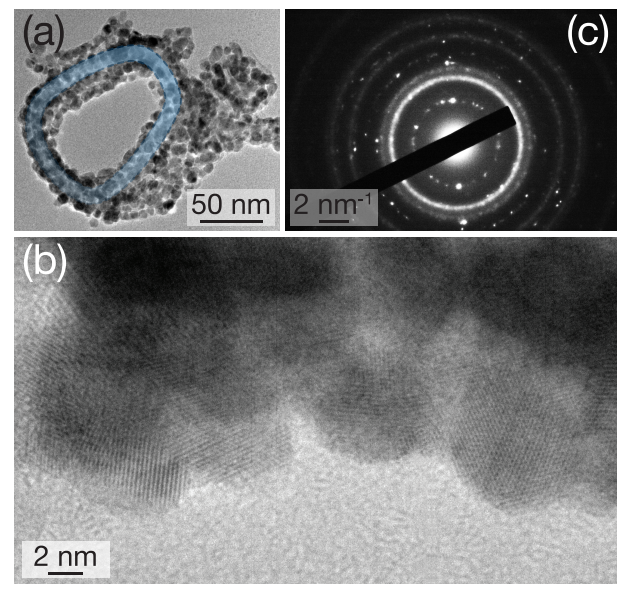

Figure 5. TEM images of Pd nanoparticles deposited $(N=500$ cycles) onto TNTs after annealing at $450^{\circ} \mathrm{C}$ for $2 \mathrm{~h}$. (a) Top view of a TNT mouth covered by Pd nanoparticles. The blue shadow highlights the position of the TNT. (b) High-resolution image of Pd particles and (c) the corresponding selected area electron diffraction. 


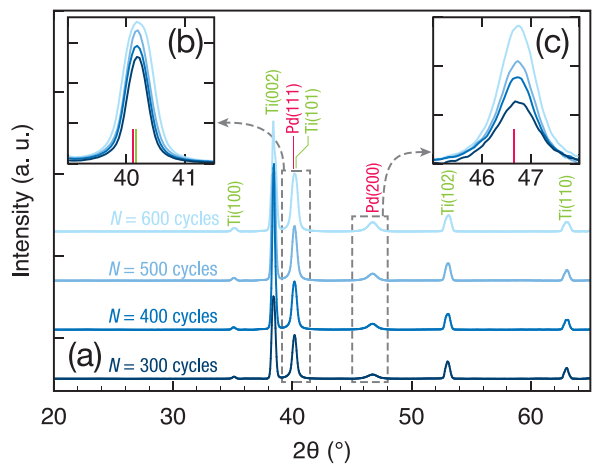

Figure 6. (a) X-ray diffractograms of TNTs after depositions of Pd nanoparticles for various number of cycles ( $N$ is indicated on the plot). The Pd and Ti diffraction planes are indicated on the corresponding peaks. (b) and (c) show an enlarged view of the $\mathrm{Pd}(111) / \mathrm{Ti}(101)$ and $\mathrm{Pd}(200)$ peaks regions, respectively. The colored bars correspond to the position of the reference peaks of $\mathrm{Pd}$ and $\mathrm{Ti}$. 


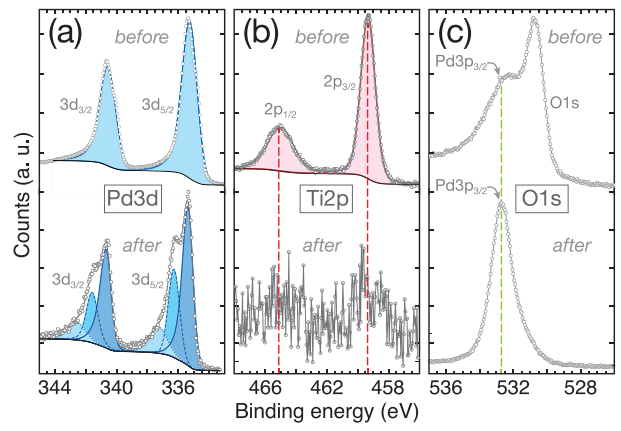

Figure 7. Pd3d (a), Ti2p (b) and O1s (c) XPS peaks before (upper spectra) and after (lower spectra) electrochemical measurements of Pd-covered TNTs ( $N=500$ cycles). 


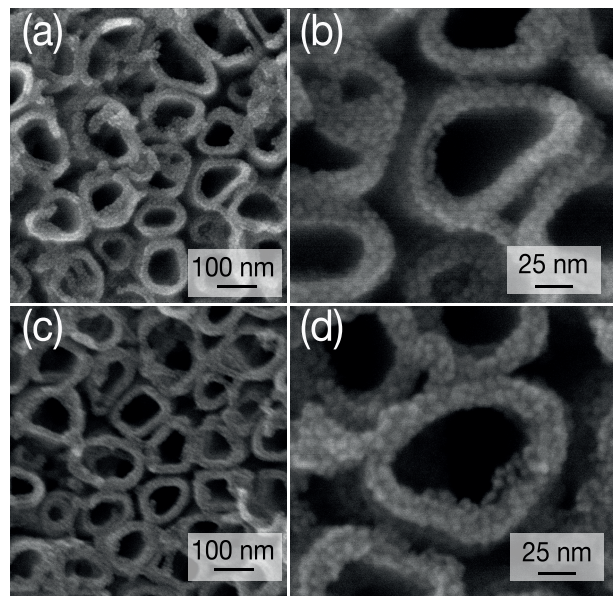

Figure 8. SEM top views of TNTs after ALD of $\mathrm{Pd}(N=500$ cycles). The Pd was deposited onto as-grown $(a, b)$ and annealed $(c, d)$ TNTs. 


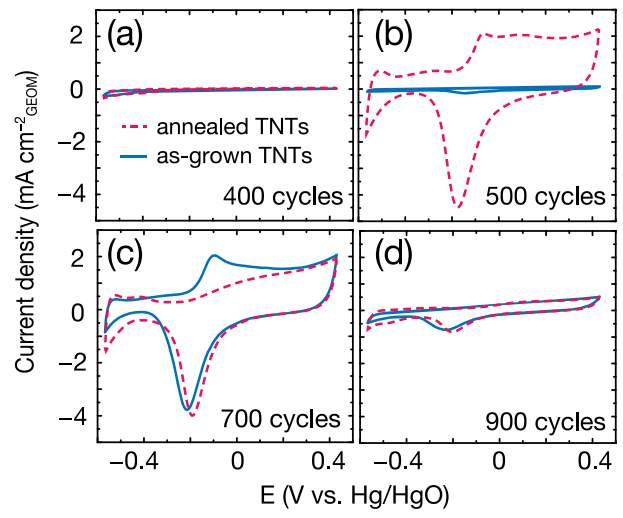

Figure 9. Cyclic voltammograms of as-grown (full line) and annealed (dashed line) TNTs after ALD of Pd for $N=400$ (a), 500 (b), 700 (c) and 900 (d) cycles. The electrolyte is $1 \mathrm{M} \mathrm{KOH}$, scan rate is $25 \mathrm{mV} \mathrm{s}^{-1}$. 


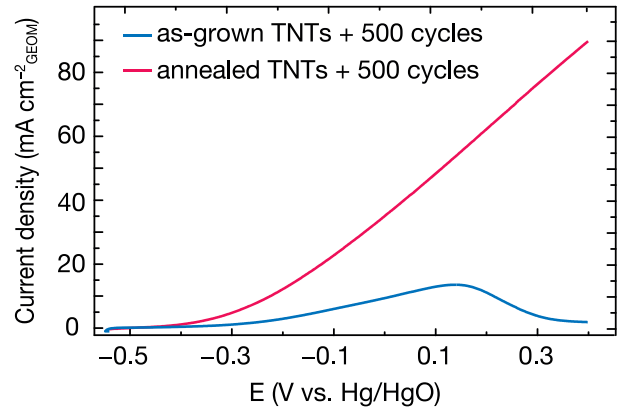

Figure 10. Cyclic voltammograms of 500 Pd ALD cycles on as-grown and annealed TNTs in $1 \mathrm{M} \mathrm{KOH}+1 \mathrm{M} \mathrm{C}_{2} \mathrm{H}_{5} \mathrm{OH}$. The scan rate is $25 \mathrm{mV} \mathrm{s}^{-1}$ and the current density is normalized by geometric surface area. 

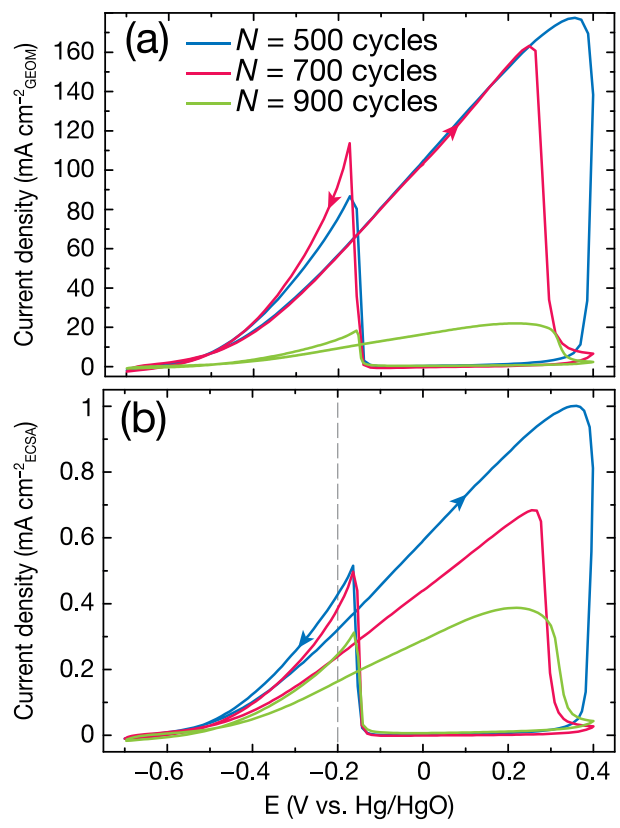

Figure 11. Cyclic voltammograms of $\mathrm{Pd} / \mathrm{TNT}$ swith various number of Pd ALD cycles on annealed TNTs in $1 \mathrm{M} \mathrm{KOH}+1 \mathrm{M} \mathrm{C}_{2} \mathrm{H}_{5} \mathrm{OH}$. Current density is given per geometrical area (a) and ECSA (b). The scan rate is $25 \mathrm{mV} \mathrm{s}^{-1}$. 


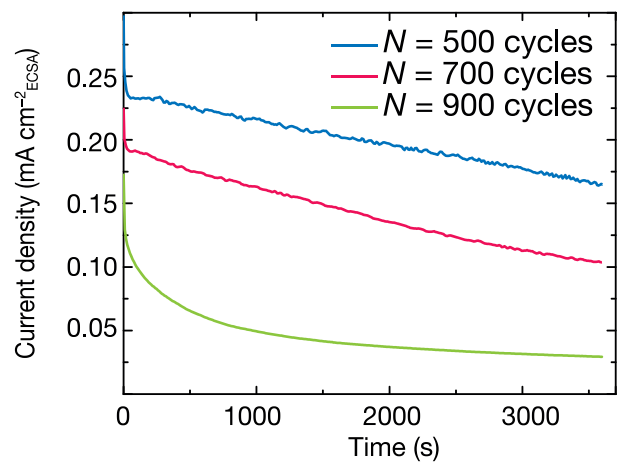

Figure 12. Comparison of the CAs in $1 \mathrm{M} \mathrm{KOH}+1 \mathrm{M} \mathrm{C}_{2} \mathrm{H}_{5} \mathrm{OH}$ of the different loadings on annealed TNTs at the potential held at $0.2 \mathrm{~V} \mathrm{vs}$. $\mathrm{Hg} / \mathrm{HgO}$ for $1 \mathrm{~h}$. 